Sussman, A. S. (1953). J. gen. Microbiol. 8, 211-216.

\title{
The Effect of Heterocyclic and other Compounds upon the Germination of Ascospores of Neurospora tetrasperma
}

\author{
By A. S. SUSSMAN \\ Department of Botany, University of Michigan, Ann Arbor, Michigan, U.S.A.
}

SUMMARY: Eleven 5-membered heterocyclic compounds, in addition to furfural and furfuryl alcohol, were effective in overcoming the dormancy of ascospores of Neurospora tetrasperma. The substitution of a nitro group in the 5-position imparted fungistatic properties to otherwise innocuous furans and pyrroles; carboxylic acid derivatives of these heterocyclic compounds likewise were toxic. From data on the time-course of furfural activation, it is shown that the $Q_{10}$ for this process is 4.1 over the temperature range from 20 to $30^{\circ}$.

The work of Shear \& Dodge (1927) and of Goddard (1935, 1939) and Goddard \& Smith (1938) established that ascospores of Neurospora spp. can be activated by heat treatment. No chemical means of inducing germination was known until Emerson (1948) showed that furfural and furfuryl alcohol are effective activators of such ascospores at concentrations as low as 1 part per million. That this effect is probably not an isolated one is suggested by the recent demonstration that furfural will also activate the spores of certain thermophilic bacteria (Mefferd \& Campbell, 1951). In order to extend the spectrum of chemical activators of ascospores of Neurospora spp., and to explore the mechanism of their action, analogues of furfural, other heterocyclic compounds, and some miscellaneous compounds having physiological activity were tested for their effect on germination.

\section{MATERIALS AND METHODS}

Ascospores were obtained by crossing strains 374 and 377 of $N$. tetrasperma which were grown as outlined by Goddard (1935). Spores were used immediately after harvesting, since Emerson (personal communication) has shown that they gradually lose their sensitivity to furfural until, after 3 months, they become almost unresponsive to such treatment; this has since been confirmed by the present author.

Tests for activators were carried out by a modification of the method described by Davies, Duckworth \& Harris (1948). After suspending the spores in $\mathbf{0 . 0 5} \%(\mathrm{w} / \mathrm{v})$ Nacconal (Allied Chemical and Dye Corp., New York, N.Y.) for a few minutes, they were rinsed 4 times by centrifugation in distilled water. Then the spores were collected on a sintered glass filter or in the bottom of centrifuge tubes and were placed in $25 \mathrm{ml}$. Erlenmeyer flasks to which had been added $5 \mathrm{ml}$. of the solutions to be tested. The flasks were shaken for $6-7 \mathrm{hr}$. at a rate of 80 oscillations $/ \mathrm{min}$. with a throw of $10 \mathrm{~cm}$. at a temperature of $25^{\circ}$. At the end of this period of time it was usually found that germination had progressed to a point where the germ tubes were about $30 \mu$. long, whereupon formaldehyde was added to the flasks in order to kill 
the spores. Two counts of at least 500 spores each were made and the average percentage germination determined; by this means an error below $5 \%$ was consistently obtained. A spore concentration of about 100,000 cells $/ \mathrm{ml}$. was used throughout.

Where the inhibitory effect of chemicals upon germination was observed, spores were washed as described previously but were then activated by heating for $30 \mathrm{~min}$. at $60^{\circ}$ in a constant-temperature oil-bath. Inoculations, incubation and counts were performed as before.

Testing of compounds was carried out using at least three dilutions, ranging from $1 \times 10^{-2} \mathrm{M}$ to $1 \times 10^{-5} \mathrm{M}$. Solvents and some other substances were used in concentrations as high as $1 \times 10^{-1} \mathrm{M}$. All compounds which were found to be active were tested for the presence of contaminant furfural by the aniline acetate test which is sensitive enough to detect up to 1 part per million of this compound. Easily polymerizable compounds like furfural, furfuryl alcohol and pyrrole were vacuum-distilled before use.

\section{RESULTS \\ Chemical activators}

As Emerson (1948) showed, furfural and furfuryl alcohol were active in breaking the dormancy of ascospores. In addition, the 11 other compounds listed in Table 1 were found to be active. The activation process shows a rather striking specific requirement for a 5-membered heterocyclic ring as repre-

Table 1. Compounds which are active in breaking the dormancy of ascospores of Neurospora tetrasperma

\begin{tabular}{|c|c|c|c|c|}
\hline & $\begin{array}{c}\text { Molar } \\
\text { activity* }\end{array}$ & $\begin{array}{c}\% \text { of } \\
\text { furfural } \\
\text { activity }\end{array}$ & Formula & $\begin{array}{l}\text { molar activity } \\
\text { measured } \\
\text { (M) }\end{array}$ \\
\hline Furfural & 248 & 100 & RCHO & $1 \times 10^{-4}$ \\
\hline 2-Furfuryl alcohol & 198 & 77 & $\mathrm{RCH}_{2} \mathrm{OH}$ & $1 \times 10^{-3}$ \\
\hline 2-Methyl furan & 189 & 76 & $\mathrm{RCH}_{3}$ & $1 \times 10^{-3}$ \\
\hline 2-Furfurylmethylether & 22 & 9 & $\mathrm{RCH}_{2} \mathrm{OCH}_{3}$ & $1 \times 10^{-2}$ \\
\hline 2-Furfural acrolein & 126 & 51 & RCH-CHCHO & $1 \times 10^{-3}$ \\
\hline 2-Furfural diacetate & 280 & 113 & $\mathrm{RCH}_{\mathrm{COOCH}_{3}}^{\mathrm{COOCH}_{3}}$ & $1 \times 10^{-4}$ \\
\hline Thiophene & 13 & 4 & $\mathbf{R}^{\prime} \mathbf{H}$ & $5 \times 10^{-4}$ \\
\hline 2-Thiophene carboxaldehyde & 198 & 80 & $\mathbf{R}^{\prime} \mathrm{CHO}$ & $1 \times 10^{-8}$ \\
\hline 2-Thiophene chloride & 214 & 86 & $\mathbf{R}^{\prime} \mathrm{Cl}$ & $1 \times 10^{-3}$ \\
\hline 2-Thiophene bromide & 94 & 38 & $\mathbf{R}^{\prime} \mathbf{B r}$ & $1 \times 10^{-3}$ \\
\hline Pyrrole & 132 & 53 & $\mathbf{R}^{\prime \prime} \mathrm{H}$ & $1 \times 10^{-2}$ \\
\hline 2-Acetyl-pyrrole & 18 & 8 & $\mathrm{R}^{\prime \prime} \mathrm{COCH}_{3}$ & $1 \times 10^{-3}$ \\
\hline Diethyl ether & 41 & 16 & $\mathrm{C}_{2} \mathrm{H}_{5} \mathrm{OC}_{2} \stackrel{\mathrm{H}}{5}_{5}$ & $1 \times 10^{-1}$ \\
\hline & $\mathbf{H}$ & & 1 & \\
\hline
\end{tabular}

* The 'molar activity' was computed by multiplying the percentage germination by the negative logarithm of the molar concentration of the compound used. The concentration giving the highest 'molar activity' was used in making the computations. 
sented by the furans, thiophenes and pyrroles, with diethyl ether as an exception to this rule.

On the other hand, many related and other heterocyclic compounds which were tested showed no activity. These included: furan, 2 -furoic acid, 2 -furoamide, 2-furoyl chloride, $n$-propyl furoate, $i s o$-amyl furoate, allyl furoate, 5-methyl-2-furoic acid, 5-bromo-2-furoic acid, 2-furfurilidine acetone, 2-furylacrylic acid, 2-furfuraldoxime, 2-furylmethylketone, 2-furfurylmercaptan, 2-nitrofuran, 5-nitro-2-furfural, 5-nitro-2-furfurylmethyl ether, furil, furoin 3-furyl acrolein, tetrahydrofuran, 2-tetrahydrofurfuryl alcohol, 2-methyltetrahydrofuran, pyrrolidine, 2:5-dihydropyrrole, and pyridine. Moreover, the following compounds which have various known physiological activities were also ineffective in activating the ascospores : adenine, adenosine, adenylic5-acid, adenosine triphosphate (ATP), thiamine, coumarin, nicotinic acid, riboflavin, imidazole, folic acid, glutathione, cysteine, cystine, indole-3-acetic acid, indole-3-propionic acid, nicotine, yeast extract, nucleic acid (yeast), casein hydrolysate (enzymatic), haemin, haemoglobin, ribose, glucose, L-proline, L-hydroxyproline, and thiazole. In all, over 120 substances were tested and, of these, only 13 (Table 1) proved to be active.

The activity of diethyl ether, although low, suggested that other organic solvents might be active. With this in mind, chloroform, acetone, light petroleum, various ethers ( $n$-propyl to $n$-amyl) and alcohols (methyl to $n$-capryl) were tested but were all inactive. It was also determined that 7 parts/1000 (approx. $1 \times 10^{-1} \mathrm{M}$ ) of diethyl ether was optimal for activation, a concentration which is far higher than that required for activation by the effective heterocyclic compounds.

Table 2. Length of time required to immerse ascospores of Neurospora tetrasperma in furfural in order to effect $50 \%$ activation

$\begin{array}{ccc} & \begin{array}{c}\text { Time necessary } \\ \text { to induce 50 \% } \\ \text { germination } \\ \text { (min.) }\end{array} & Q_{10} \\ \text { Temperature } & 34 & 4 \cdot 1 \\ 20^{\circ} & 34 & 2 \cdot 0 \\ 30^{\circ} & 8 & \\ 35^{\circ} & 5 \cdot 5 & \end{array}$

In order to determine the speed with which chemical activation is effected, $40 \mathrm{mg}$. of spores were suspended in $4 \mathrm{ml}$. of $5 \times 10^{-4} \mathrm{M}$-furfural and were incubated at various temperatures. At intervals thereafter, $0.1 \mathrm{ml}$. samples were withdrawn, washed in $0.005 \%(\mathrm{w} / \mathrm{v})$ Nacconal, rinsed three times in distilled water (found to be sufficient to remove all measureable traces of furfural), and reincubated in distilled water. Controls were treated similarly except that they were re-incubated in furfural. Counts were made as described previously, and the time necessary to effect $50 \%$ activation was determined. These results and the $Q_{10}$ calculated from this data are tabulated in Table 2. 


\section{Chemical inhibitors of ascospore germination}

During the course of the previous experiments it was observed that many of the compounds that were inactive as activators prevented the germination of heat-activated ascospores. Because of the marked sensitivity of the old spores to poisoning by heterocyclic compounds, these were used in the following experiments with inhibitors. Such old spores showed up to $70 \%$ germination when heat activated but only $15 \%$ when treated with furfural. As a result of these experiments it became apparent that the substitution of a nitro group in the 5-position of an otherwise innocuous heterocyclic compound greatly enhanced its toxicity. A number of such compounds was tested and their toxicity was compared with that of the parent compound, as shown in Table 3.

Table 3. Effect of the substitution of a nitro-group in the 5-position on the toxicity of furans to germination of ascospores of Neurospora tetrasperma

(Spores activated by heating at $60^{\circ}$ for $30 \mathrm{~min}$.)

$\begin{array}{lc} & \begin{array}{c}\text { Concentration to cause } \\ 50 \% \text { inhibition } \\ \text { of germination } \\ \text { Compound }\end{array} \\ \text { Furan } & >1 \times 10^{-2 *} \\ \text { 2-Nitrofuran } & 5 \times 10^{-4} \\ \text { 2-Furfuraldoxime } & \mathbf{1} \times \mathbf{1 0}^{-3 *} \\ \text { 5-Nitro-2-furfuraldoxime } & 5 \times 10^{-4} \\ \text { 2-Furfurylmethylether } & >1 \times 10^{-2 *} \\ \text { 5-Nitro-2-furfurylmethylether } & 4 \times 10^{-4} \\ \text { 2-Furfurylidine acetone } & >1 \times 10^{-3 *} \\ \text { 5-Nitro-2-furfurylidine acetone } & 5 \times 10^{-3} \\ \text { 2-Acetylpyrrole } & >1 \times 10^{-3 *} \\ \text { 5-Nitro-2-acetylpyrrole } & 4 \times 10^{-4}\end{array}$

* These figures were not defined more precisely because of the insolubility of the compounds.

Table 4. Heterocyclic compounds which inhibit germination of ascospores of Neurospora tetrasperma

(Spores activated by heating at $60^{\circ}$ for $30 \mathrm{~min}$.)

\section{Concentration required to cause $50 \%$ inhibition of \\ germination}

Compound

2-Furoic acid

5-Bromo-2-furoic acid

2-Furyl acrylic acid

2-Pyrrole carboxylic acid

3-Pyrrole carboxylic acid

2-Furyl acrolein

3-Furyl acrolein
(M)

$2 \times 10^{-4}$

$3 \times 10^{-4}$

$5 \times 10^{-4}$

$>1 \times 10^{-3 *}$

$4 \times 10^{-4}$

$>1 \times 10^{-4 *}$

$8 \times 10^{-4}$

* These figures were not defined more precisely because of the insolubility of the compounds. 
Table 4 lists the other chemicals found to be toxic to germinating ascospores, and it is at once apparent that heterocyclic carboxylic acids, as a group, are among the most toxic of these chemicals. It should also be noted that the sodium and potassium salts of these acids were relatively non-toxic, as might be expected on the basis of the more ready penetration of the free acid, Finally, experiments were conducted with these substances in which the inhibitors were washed from the spores by immersion in Nacconal followed by several rinses with distilled water. The fact that the washed spores germinated normally demonstrated that the inhibitors used were fungistatic rather than fungicidal.

\section{DISCUSSION}

That chemical activators of ascospore germination function in a catalytic role is suggested by the specificity of 5-membered heterocyclic ring compounds in breaking dormancy, and by the small amounts of these compounds required for the activation. On the basis of the preceding experiments, certain generalizations can be made as to the relation between chemical structure and activity among these heterocyclic compounds:

(1) Of the furans and pyrroles tested, only the fully unsaturated compounds were active (tetrahydrofurfuryl alcohol, pyrrolidine and 2:5-dihydropyrrole were inactive in contrast to their completely unsaturated analogues).

(2) The hetero-atom may be either oxygen, nitrogen or sulphur (furans, pyrrole and thiophenes were active).

(3) Conjugated derivatives are not active (haemoglobin, haemin, furoin and furil failed to activate).

The quantitative comparisons given in Table 1 suggest that certain of the furans are the most active, on a molar basis, of the compounds tested. However, it must be remembered that such comparisons are complicated by factors such as permeability, resistance to inactivation by enzymes, etc., so that many secondary characteristics may influence the activity of a compound (Thimann, 1951).

Not much more can be stated positively about the relation between structure and activity than that which is listed above. The active heterocyclic compounds comprise a diverse group of chemical structures, and this fact, together with the observation that diethyl ether is also active, argues against a specific role for heterocyclic compounds in the activation process. Nevertheless, there are certain reasons for believing that such a role does exist. These include: (i) the small amounts required for activation (diethyl ether is required in concentrations as high as $1 \times 10^{-1} \mathrm{M}$ as compared with the heterocyclic compounds effective as low as $1 \times 10^{-4} \mathrm{M}$ ); (ii) the toxicity of compounds closely related to activators suggests that inhibition of a key reaction, or reactions, by a structural analogue occurs; (iii) the $Q_{10}$ for furfural activation between 20 and $30^{\circ}$ is $4 \cdot 1$, suggesting that a chemical reaction is occurring.

It should also be recalled that some parallels exist between the structural requirements for ascospore activation, and synthetic and naturally occurring higher plant growth regulators. In the latter groups of compounds, several deviations from the main pattern of active structural configuration have also 
been observed (Sexton, 1950), but it is still felt that the specificity of certain structures is evidence for their participation in key enzyme reactions (Thimann, 1951). The fact that certain analogues of furfural and pyrrole antagonize the germination process suggests that the use of such specific inhibitors may provide another means of approach to the problem of ascospore activation in Neurospora spp.

I wish to thank: Prof. D. R. Goddard who first introduced me to this problem and furnished invaluable help and guidance during my tenure of a National Research Council Fellowship at the University of Pennsylvania during the year 1949-50; the American Cancer Society and the Rackham Fund of the University of Michigan for financial support during some of these investigations; Dr B. O. Dodge for his kindness in sending the cultures of Neurospora tetrasperma used in this work; Dr J. Yurchenko of the Eaton Laboratories who furnished the nitrated derivatives used in these experiments.

The co-operation of the research laboratories of the following organizations greatly simplified the course of this work: Cargille Scientific, Inc., New York 6, N.Y.; Commercial Solvents Corp., Terre Haute, Indiana ; E. I. Du Pont de Nemours and Co., Inc., Wilmington, Delaware ; Eaton Laboratories, Inc., Norwich, New York; Monsanto Chemical Co., St Louis 4, Missouri; The Quaker Oats Company, New York, N.Y.; Reilly Tar and Chemical Corp., Indianapolis, Indiana; F. Ritter and Co., Los Angeles 26, California; Union Carbide and Carbon Corp., New York 17, N.Y.

\section{REFERENCES}

Davies, O. L., Duckworth, R. B. \& Harris, G. M. C. (1948). Method for estimating percentage germination of fungal spores. Nature, Lond. 161, 642.

Emerson, M. R. (1948). Chemical activation of ascospore germination in Neurospora crassa. J. Bact. 55, 327.

GoDdARD, D. R. (1935). The reversible heat activation inducing germination and increased respiration in the ascospores of Neurospora tetrasperma. J. gen. Physiol. 19, 45.

GodDARD, D. R. (1939). The reversible heat activation of respiration in Neurospora. Cold Spr. Harb. Symp. quant. Biol. 7, 362.

Goddard, D. R. \& Smith, P. E. (1938). Respiratory block in the dormant spores of Neurospora tetrasperma. Plant Physiol. 13, 241.

MefFerd, Jr., R. B. \& CAMPBeli, Jr., L. L. (1951). The activation of thermophilic spores by furfural. J. Bact. 62, 130.

Sexron, W. A. (1950). Chemical Constitution and Biological Activity. London: Van Nostrand.

Shear, C. L. \& Dodge, B. O. (1927). Life histories and heterothallism of the red bread-mold fungi of the Monilia sitophila group. J. agric. Res. 34, 1019.

Thrmans, K. V. (1951). The synthetic auxins: relation between structure and activity. Chapter in Plant Growth Substances. Ed. Skoog, F. Wisconsin University Press. 